\title{
BAHASA ARAB DAN PROBLEMATIKA TRANSLITERASI
}

\author{
Muhammad Alif (iD \\ Universitas Islam Negeri Sultan Maulana Hasanuddin Banten \\ muhammad.alif@uinbanten.ac.id
}

\section{Abstrak:}

Transliterasi adalah transisi dari suatu sistem literasi suatu bahasa ke sistem literasi bahasa lainnya. Bahasa Arab yang memiliki fonologi unik dan grafologi yang tak memiliki hutuf vocal kecuali dengan tambahan diakritik di atas atau bawah huruf, menjadikan bahasa Arab memiliki kompleksitas untuk ditransliterasi. Pasalnya karena sebagian besar teks-teks Arab ditulis tanpa diakritik/harakat karena penulis mengasumsikan setiap pembaca teks Arab dapat membaca pelafalannya meski tanpa harakat. Selain itu penulisan teks Arab dengan menuliskan diakritiknya memakan waktu yang tidak sedikit. Artikel ini membahas tentang transliterasi Arab-Indonesia, problematika dan penerapannya.

Kata kunci: Fonologi Arab; Sistem Aksara Bahasa; Transliterasi

\section{Bahasa Arab, Lugah Ḍād}

Bahasa Arab, baik secara grafologi maupun fonologi merupakan bahsa yang mempunyai banyak keunikan. Secara grafologi, setiap huruf dalam bahasa Arab perlu perubahan pola penulisan ketika huruf itu berada di depan, tengah atau belakang. Huruf-huruf Arab hanya mengenal konsonan dan tidak huruf vokal. Huruf-huruf konsonan Arab tidak mengenal padanan lafal $C \& P$ serta kombinasi dua huruf konsonan semisal NY (seperti pada kata nyamuk) dan NG (seperti pada kata singa). Huruf-huruf vokal Arab diwakili dengan diakritik berupa harakat yang diletakkan di atas atau di bawah huruf konsonan yang pelafalannya sepadan dengan A, I dan U. Harakat Arab tidak mengenal padanan pelafalan huruf vokal E 
dan O. Secara fonologi beberapa huruf dalam sistem aksara Arab ada beberapa huruf yang jarang ada pada fonologi bahasa lain. Seperti ض ص ص ط ح ح. Bahasa Arab dikenal dengan lugah al-ḍād, karena diyakini ض dengan fonem khas bahasa Arab tidak ada dalam fonologi bahasa lain manapun, karena huruf ض adalah huruf yang paling susah dilafalkan. ${ }^{1}$ Konon istilah ini diambil dari hadis Nabi: أنا أفصح من نطق بالضاد بيد أني من قريش. Hadis ini oleh Ibn Kaṡīr dinilai tidak ada asal-usulnya, Ibn Hajar menambahkan: "hadis ini makna matanya șahịh, tetapi tidak ada asalusulnya. ${ }^{2}$ Pendapat ini diperkuat dengan hasil penelitian Hasan 'Abd al-Majīd 'Abbās al-Syā'ir yang meneliti 16 hadis terkait. ${ }^{3}$ Menurut al-Syā'ir sekiranya hadis ini benar, makan matan hadis ini aslinya diperkirakan matannya cukup ringkas, lalu ada banyak versi penambahan, termasuk penambahan man națaqa bi al-ḍād. ${ }^{4}$ Dalam bahasa Indonesia fonem dan grafem ض dialihaksarakan dengan "dh" atau "dl." Bahkan kata ضرورو yang dicerap ke dalam bahasa Indonesia dengan kata darurat huruf ض diwakili dengan memakai huruf "d" saja tanpa dikombinasi dengan huruf "h" ataupun "I."

\section{Pengertian Transliterasi}

Secara etimologi transliterasi bermakna: "penyalinan dengan penggantian huruf dari abjad yang satu ke abjad yang lain." ${ }^{5}$ Transliterasi dalam Kamus Istilah Filologi didefinisikan sebagai "pengubahan teks dari satu tulisan ke tulisan yang

\footnotetext{
1 Alekhbariya.net. 2020. لماذا سميت اللغة العربية بلغة "الضاد"؟ | الإخبارية. [online] Available at: <http://alekhbariya.net/ar/node/38461\#: :text=\%D8\%B3\%D9\%85\%D9\%8A\%D8\%AA\%20\%D8\%A7\%D9\%84 \%D9\%84\%D8\%BA\%D8\%A9\%20\%D8\%A7\%D9\%84\%D8\%B9\%D8\%B1\%D8\%A8\%D9\%8A\%D8\%A9\%20\%D 8\%A8\%D9\%80\%20\%E2\%80\%9D\%20\%D9\%84\%D8\%BA\%D8\%A9,\%D8\%A8\%D8\%A7\%D9\%84\%D9\%85\% D8\%B9\%D8\%A7\%D9\%86\%D8\%A7\%D8\%A9\%D8\%8C\%20\%D9\%83\%D9\%85\%D8\%A7\%20\%D8\%A3\%D9\% 86\%20\%D8\%A7\%D9\%84\%D8\%A3\%D8\%B4\%D8\%AE\%D8\%A7\%D8\%B5\%20\%D8\%A7\%D9\%84\%D8\%B0\% D9\%8A\%D9\%86> [Accessed 17 October 2020].

2 www.alukah.net. 2020. حديث: أنا أفصح من نطق بالضاد بيد أني من قريش. [online] Available at: <https://www.alukah.net/sharia/0/51166/> [Accessed 17 October 2020].

${ }^{3}$ Heasan 'Abd al-Majīd 'Abbās al-Syā'ir, 2020. Hadīṣ Al-Rasūl (Șallā Allāh 'Alaih Wasallam): "Anā Afșaḥ Al'Arab Baida Annī Min Quraisy" Sanaduhu Wa Riwāyatuhu Wa Ra'Yu Al-'Ulamā' Fīhi -- Dalālatuhu. [online], Journals.uokufa.edu.iq. 159. Available at: <http://journals.uokufa.edu.iq/index.php/arll/article/view/2307/1972> [Accessed 17 October 2020].

${ }^{4}$ Al-Syā'ir, "Hadìs al-Rasūl," 166.

${ }^{5}$ Hasil Pencarian - KBBI Daring, 17 Oktober 2020, https://kbbi.kemdikbud.go.id/entri/Transliterasi.
} 
lain atau dapat disebut alih huruf atau alih aksara, misalnya dari huruf Jawa ke huruf Latin, dari huruf Sunda ke huruf Latin, dan sebagainya". ${ }^{6}$

Secara terminologi Transliterasi adalah "proses atau hasil pengalihan tanda grafik dari satu sistem tulisan kepada sistem tulisan lain. Teknis transliterasi melalui proses tiga langkah: pertama, mengalihkan unit grafologi bahasa sumber ke unit fonologi bahasa sumber; kedua, mengalihkan unit fonologi bahasa sumber ke unit fonologi bahasa sasaran; ketiga, mengalihkan unit fonologi bahasa sasaran ke grafologi bahasa sasaran. ${ }^{7}$ Transliterasi dalam Google Input Tools merujuk pada metode pemetaan dari satu sistem penulisan ke sistem penulisan lain berdasarkan pada kesamaan fonetik. ${ }^{8}$ Transliterasi menurut Onions adalah suntingan yang disajikan dengan jenis tulisan lain. Menurut Baried transliterasi adalah penggantian jenis tulisan, huruf demi huruf dari satu abjad ke abjad yang lain. ${ }^{9}$

Dari beberapa pengertian transliterasi di atas dapat disimpulkan bahwa transliterasi bukan hanya sekedar alih aksara dari satu jenis aksara ke jenis aksara lain, tetapi harus dikaitkan dengan sistem aksara suatu bahasa. Aksara latin yang banyak dipakai dalam banyak bahasa misalnya, meski bentuknya sama dari A - Z, tapi pelafalannya sangat beragam sesuai fonologi suatu bahasa. Sebut saja contohnya huruf J. Dalam bahasa Indonesia sesuai EYD dilafalkan dengan "je", dalam ejaan lama dilafalkan dengan "ye" (peralihan tulisan Jogjakarta menjadi Yogyakarta, kiranya dapat memberikan gambaran tentang ini). J dalam bahasa Spanyol dilafalkan dengan "he". Lagu Asereje yang tenar pada tahun 2002 menyadarkan banyak orang bahwa ternyata lafal aserehe yang akbrab ditelinga ternyata tulisannya asereje. Atas dasar itu transliterasi Arab-Latin dalam sistem

\footnotetext{
${ }^{6}$ 2020. Ebook. 2

https://www.google.com/url?q=http://staffnew.uny.ac.id/upload/132303685/pendidikan/materitransliterasi.pdf\&sa=U\&ved=2ahUKEwjYnljvubrsAhXO6XMBHSjHB2UQFiABegQICXAB\&usg=AOvVaw3NJJN eht BiKWm339053q1

${ }^{7}$ Azman Mat dan Ahmad Yaakub. 2020. "Kegunaan Transliterasi Dalam Pengajaran Dan Pembelajaran Bahasa Arab". Ejournal.Ukm.My. http://ejournal.ukm.my/gema/article/view/107. 20

${ }^{8}$ Transliterasi - Google Input Tools". 2020. Google.Com, 17 Oktober 2020, https://www.google.com/int//id/inputtools/services/features/transliteration.html.

${ }^{9}$ 2020. Ebook. 2
} 
aksara Indonesia tentu berbeda dengan transliterasi Arab-Latin dalam sistem aksara bahasa Inggris. Tulisan "hadith" jika dibaca dengan sistem aksara bahasa Inggris tentu mendekati transliterasi "حديث", tapi dalam sistem aksara bahasa Indonesia tulisan "hadits" (pelafalan secara tipis huruf t digabung kan lafal huruf s) lebih mendekati makhraj $ث$.

\section{Pedoman Transliterasi}

Pedoman Transliterasi Arab Latin yang merupakan hasil keputusan bersama (SKB) Menteri Agama dan Menteri Pendidikan dan. Kebudayaan R.I. Nomor: 158 Tahun $1987^{10}$ disusun sesuai sistem aksara Indonesia yang tidak mengenal kombinasi dua huruf kecuali kh (misal: khalayak), sy (misal: masyarakat), ps (psikologi), sehingga transliterasi konvensional seperti aa(七), ii(s), uu(وُ)), ts (ث)), dz(ذ), dh(ض), dl(ض), zh(ظ), th(ط), sh(ص), gh(غ). SKB tersebut mengganti kombinasi dua huruf konsonan yang tidak dikenal oleh sistem alfabet Indonesia dengan satu huruf yang dikombinasikan dengan titik, baik di atas atau di bawah huruf, serta mengganti kombinasi dua huruf vokal dengan satu huruf vokal dikombinasikan dengan garis di atas huruf vokal. Pedoman Transliterasi SKB nomor 158 ini secara metode, diistilahkan dengan transliterasi metode diplomatik, yaitu penggantian jenis tulisan, huruf demi huruf dari sistem abjad yang satu ke ke sistem abjad yang lain apa adanya. Kriteria metode ini adalah bahwa setiap bentuk aksara dan visualisasi wujud teks dalam naskah yang ditransliterasi harus terwakili dalam hasil transliterasi. Oleh sebab itu, untuk mempertahankan visualisasi wujud teks, diperlukan pedoman transliterasi. ${ }^{11}$

Pedoman Transliterasi SKB Nomor. 158 di atas meski sudah maksimal menyesuaikan dengan sistem aksara bahasa Indonesia, tapi masih ada beberapa kelemahan. Kelemahan pertama huruf $\dot{\varepsilon}$ dalam pedoman transliterasi tersebut hanya dilambangkan dengan huruf "g" padahal fonem $\dot{\varepsilon}$ dan $g$ tidak identik

\footnotetext{
${ }^{10}$ Pedoman Transliterasi Arab Latin. 2003. Jakarta: Departemen Agama RI, Badan Litbang Agama dan Diklat Keagamaan, Proyek Pengkajian dan Pengembangan Lektur Pendidikan Agama.

11 2020. Ebook. 4-6
} 
sehingga memerlukan pembedaan. Misalnya dengan $g$ dikombinasi titik atas menjadi g. Kelemahan kedua, meski kh dan sy dalam sistem aksara bahasa Indonesia identik dengan sistem aksara Arab $\dot{\tau}$ dan pasangan huruf ini (kh dan sy) tetap memerlukan lambang pembeda untuk menunjukkan bahwa kedua pasang huruf itu harus dibaca satu fonem untuk menghindari kesamaan alih aksara untuk dua kata yang berbeda. Misalnya: kata "إمسِكْكَ (tahanlah dia) jika dialihaksarakan dengan imsikhu, pembaca yang tak mengenal bahasa Arab akan membaca dua cara: imsikhu ( $\mathrm{k}$ dan $\mathrm{h}$ dilafalkan dengan satu fonem: إمْنسخ pelafalan yang keliru dan merubah arti) atau imsikhu ( $k$ dan $\mathrm{h}$ dilafalkan dengan dua fonem: أمْنسكْهِ pelafalan yang benar). Begitu juga dengan kata نَسِيَّان (lupa/kelupaan) jika dialihaksarakan dengan nisyān akan dibaca antara dua cara nisyān (s dan y dilafalkan dengan dua fonem sehingga fonem Arabnya menjadi نِنِيَّان pelafalan yang tepat) atau dengan cara nisyān (s dan y dilafalkan dengan satu fonem Arabnya menjadi نِنَّان pelafalan yang keliru dan merubah arti). Kelemahan berikutnya bahwa pedoman transliterasi di atas tidak menekankan secara tegas antara sukun/taskīn akhir kata dan ي nisbah akhir

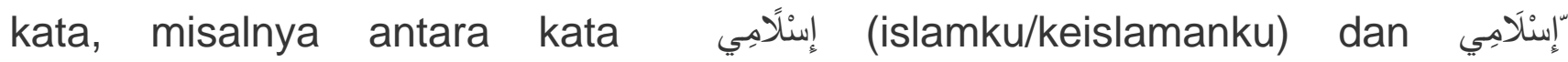
(keislaman/bersifat keislaman), sehingga secara praktek banyak penulis yang mengalihaksarakan keduanya dengan islāmī, bukan membedakan dua alih aksara antara islāmī dan islāmiy.

\section{Transliterasi dan Problem Ketersediaan Sarana}

Para penulis yang biasa memakai aplikasi pengolah kata Microsoft Word, sebelum ada Latin Extended-A pada map insert symbol, hanya mampu menerapkan penggantian dua huruf vokal dengan Â/â, î/î, Û/û (kombinasi 1 huruf vokal dengan caret di atas huruf. Sedang untuk pengganti kombinasi konsonan ganda para penulis 'pasrah' memakai transliterasi konvensional. Setelah ada penambahan Latin Extended A, sebagian penulis mulai dapat menulis huruf-huruf

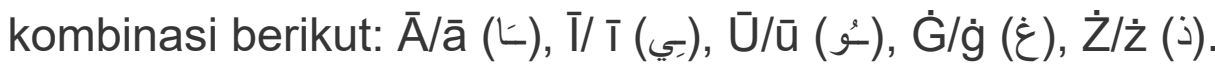


Beberapa pihak membuat jenis font yang mendukung kombinasi huruf dengan diakritik, baik di atas maupun di bawah huruf. Dan yang cukup terkenal adalah Time New Arabic, dan Transliterasi Alif yang tidak populer. Kendalanya font tersebut hanya mengacu kepada satu fontface saja misalnya serif atau san-serif. Serta untuk bisa dibaca pada device lain font tersebut harus terinstal kecuali file PDF yang mampu menyematkan font tersebut ke dalam file dokumen. Sehingga jika dokumen tersebut dicopy-paste, maka tulisan yang muncul adalah tulisan asli tanpa dukungan font tersebut.

Table perbandingan tampilan

Font Time New Arabic.ttf dan Transliterasi Alif.ttf

\begin{tabular}{|c|c|c|}
\hline Arab & $\begin{array}{l}\text { Tampilan dengan } \\
\text { dukungan font }\end{array}$ & $\begin{array}{l}\text { Tampilan tanpa } \\
\text { dukungan font }\end{array}$ \\
\hline \multicolumn{3}{|c|}{ FONT Times New Arabic } \\
\hline$\dot{~}$ & $\dot{S} / \dot{s}$ & $\mathrm{~S} \mid / \mathrm{s} \backslash$ \\
\hline$\tau$ & $\mathrm{H} / \mathrm{h}$ & $\mathrm{H}\{\mathrm{/} h\}$ \\
\hline$\dot{j}$ & Ż/ż & $\mathrm{Z} \mid / \mathrm{zl}$ \\
\hline ص ص & Ș/ș & $S\{/ s\}$ \\
\hline 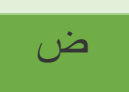 & $\mathrm{D} / \mathrm{d}$ & $D\{/ d\}$ \\
\hline b & Ṭ/ț & $\mathrm{T}\{/ \mathrm{t}\}$ \\
\hline ظ & $Z / Z$ & $\mathrm{Z}\{/ \mathrm{z}\}$ \\
\hline 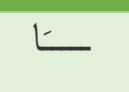 & $\overline{\mathrm{A}} / \bar{a}$ & $A</ a\{$ \\
\hline - & $\overline{\mathrm{T}} / \overline{\mathrm{T}}$ & I@ / i< \\
\hline 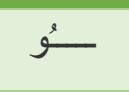 & $\bar{U} / \bar{u}$ & $\mathrm{U}</ \mathrm{U}<$ \\
\hline \multicolumn{3}{|c|}{ FONT TRANSLITERASI ALIF v. 1} \\
\hline$\dot{ث}$ & $\dot{S} / \dot{S}$ & Ś/ś \\
\hline$\tau$ & $\mathrm{H} / \mathrm{h}$ & $\hat{\mathrm{H}} \_\hat{h}$ \\
\hline$\dot{j}$ & $\dot{Z} / \dot{z}$ & $\dot{Z} / \dot{z}$ \\
\hline 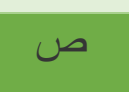 & Ș/ș & Ş/Ş \\
\hline 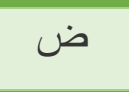 & $\mathrm{D} / \mathrm{d}$ & Đ/đ \\
\hline b & $\mathrm{T} / \mathrm{t}$ & $\mathrm{T} / \mathrm{t}$ \\
\hline
\end{tabular}




\begin{tabular}{|c|c|c|}
\hline ط & Z $/ \mathrm{Z}$ & Ž/Ž \\
\hline$L$ & $\overline{\mathrm{A}} / \overline{\mathrm{a}}$ & $\overline{\mathrm{A}} / \overline{\mathrm{a}}$ \\
\hline - & Ī/T & $\overline{\mathrm{I}} / \overline{\mathrm{T}}$ \\
\hline : & $\overline{\mathrm{U}} / \overline{\mathrm{u}}$ & $\overline{\mathrm{U}} / \overline{\mathrm{u}}$ \\
\hline
\end{tabular}

Kini, setelah Microsoft Word menambahkan Latin Extended Additional untuk melengkapi yang sebelumnya hanya Latin Extended-A dan Latin Extended-B, maka semua pedomanTransliterasi SKB tersebut dapat diterapkan dengan jenis font apapun, dan dapat ditampilkan pada device mana pun, termasuk di browser dan Smartphone. Termasuk artikel ini yang menggunakan font roboto.ttf Untuk menampilkan huruf tersebut pada word cukup insert symbol dan pilih pada

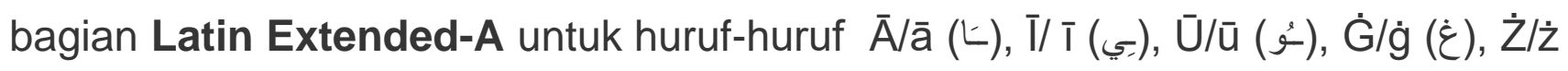
(ذ) dan pada bagian Latin Extended Additional untuk huruf-huruf $\dot{S} / \dot{\mathbf{s}}(\dot{)}), \mathrm{H} / \mathrm{h}$ ( (ح)), Ș/ṣ (ص), Ḍ/ḍ (ض), Ṭ/ṭ (b), Ẓ̣̌̂ (ظ).

Cara lain menulis transliterasi pada word:

1. Buat shortcut key tiap huruf paduan antara crtl shift alt

2. Buat shortcut pada toolbar

3. Ketik kode hexadesimal unicode lalu tekan alt lalu tekan $x$ (lihat tabel unicode di bawah) cara ini juga bisa diterapkan pada Smartphone android dengan aplikasi Hacker's keyboard

4. Membuat keyboard virtual dengan macro atau vba word dengan kode selection.type chrw(nomer unicode)

5. Menggunakan aplikasi special virtual keyboard seperti AutoHotkey, MSKLC dan KBDUsGer

6. Memakai word template ALIF TRANS UIN BANTEN yang sudah dibuatkan keyboard transliterasi di sini 


\begin{tabular}{|c|c|c|c|c|}
\hline Arab & $\begin{array}{c}\text { Indonesi } \\
\text { a }\end{array}$ & Inggris & Hexa Unicode & Shortcut in Ms. Word \\
\hline 1 & & & & \\
\hline ب & $B / b$ & $B / b$ & & \\
\hline$ت$ & $\mathrm{~T} / \mathrm{t}$ & $\mathrm{T} / \mathrm{t}$ & & \\
\hline$\dot{\leftrightarrow}$ & $\dot{S} / \dot{S}$ & Th/th & 1 e60 / 1e61 & 1e60+Alt x / 1e61+Alt x \\
\hline ج & $\mathrm{J} / \mathrm{j}$ & $\mathrm{J} / \mathrm{j} / \mathrm{G} / \mathrm{g}$ & & \\
\hline$\tau$ & $H / h$ & $\mathrm{H} / \mathrm{h}$ & $1 \mathrm{e} 24$ / 1e25 & 1e24+Alt x / 1e25+Alt x \\
\hline$\dot{\tau}$ & $\mathrm{Kh} / \mathrm{kh}$ & $\mathrm{Kh} / \mathrm{kh}$ & & \\
\hline 2 & $D / d$ & $D / d$ & & \\
\hline$\dot{j}$ & $\dot{Z} / \dot{z}$ & $\dot{Z} / \dot{z}$ & 017b / 017c & $017 b+$ Alt $x / 017 c+$ Alt $x$ \\
\hline J & $\mathrm{R} / \mathrm{r}$ & $\mathrm{R} / \mathrm{r}$ & & \\
\hline j & $\mathrm{Z} / \mathrm{Z}$ & $\mathrm{Z} / \mathrm{Z}$ & & \\
\hline 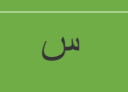 & $\mathrm{S} / \mathrm{s}$ & $\mathrm{S} / \mathrm{s}$ & & \\
\hline 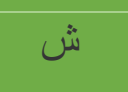 & Sy/sy & $\mathrm{Sh} / \mathrm{sh}$ & & \\
\hline ص ص ص & Ș/ș & Ș/ș & 1 e62 / 1e63 & 1e62+Alt x / 1e63+Alt x \\
\hline 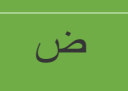 & D/d & $\mathrm{D} / \mathrm{d}$ & $1 e 0 c / 1 e 0 d$ & $1 \mathrm{e} 0 \mathrm{c}+$ Alt $x / 1 \mathrm{e} 0 \mathrm{~d}+$ Alt $x$ \\
\hline$b$ & $T / t$ & $T+t \underline{t}$ & $1 \mathrm{e} 6 \mathrm{c} / 1 \mathrm{e} 6 \mathrm{~d}$ & $1 \mathrm{e} 6 \mathrm{c}+$ Alt $x / 1 \mathrm{e} 6 \mathrm{~d}+$ Alt $x$ \\
\hline ظ & $Z / Z$ & $\mathrm{Z} / \mathrm{Z}$ & 1 e92 / 1e93 & 1e92+Alt x / 1e93+Alt x \\
\hline$\varepsilon$ & & & 2018 & 2018+Alt x \\
\hline$\dot{\varepsilon}$ & $\mathrm{G} / \mathrm{g}$ & $\dot{\mathrm{G}} / \dot{\mathrm{g}}$ & 0120 / 0121 & $0120+$ Alt x / 0121+Alt x \\
\hline ق & $\mathrm{Q} / \mathrm{q}$ & $Q / q$ & & \\
\hline 5) & $\mathrm{K} / \mathrm{k}$ & $\mathrm{K} / \mathrm{k}$ & & \\
\hline ف & $F / f$ & $F / f$ & & \\
\hline J & L/l & L/l & & \\
\hline 5 & $\mathrm{M} / \mathrm{m}$ & $\mathrm{M} / \mathrm{m}$ & & \\
\hline ن & $N / n$ & $N / n$ & & \\
\hline 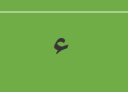 & & & 2019 & 2019+Alt x \\
\hline ي & $Y / y$ & $\mathrm{Y} / \mathrm{y}$ & & \\
\hline
\end{tabular}




\begin{tabular}{|c|c|c|c|c|}
\hline 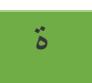 & $\mathrm{h}$ & h & & \\
\hline 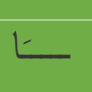 & $\overline{\mathrm{A}} / \overline{\mathrm{a}}$ & $\overline{\mathrm{A}} / \overline{\mathrm{a}}$ & 0100 / 0101 & 0100+Alt x / 0101+Alt x \\
\hline - & $\overline{\mathrm{T}} / \overline{\mathrm{T}}$ & $\overline{\mathrm{I}} / \overline{\mathrm{T}}$ & $012 a / 012 b$ & $012 a+$ Alt x / 012b+Alt x \\
\hline$\stackrel{2}{2}$ & $\bar{U} / \bar{u}$ & $\bar{U} / \bar{u}$ & $016 a / 016 b$ & $016 a+$ Alt x / 016b+Alt x \\
\hline 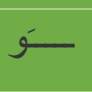 & $\mathrm{Au} / \mathrm{au}$ & & & \\
\hline 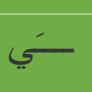 & $\mathrm{Ai} / \mathrm{ai}$ & & & \\
\hline
\end{tabular}

Penulisan kata majemuk dapat dilakukan menurut alih aksara kata perkata atau ali $h$ bunyi.

\begin{tabular}{ll}
\hline Transliterasi & Transkripsi \\
\hline 'Abd Allāh & 'Abdullāh, 'Abdillāh, 'Abdallāh \\
\hline Nāșir al-Dīn & Nāșiruddīn \\
\hline Sidrah al-Muntahā & Sidratul-Muntahā \\
\hline Syu'ab al-Īmān & Syu'abul-Īmān \\
\hline
\end{tabular}

\section{REFERENSI}

"Transliterasi - Google Input Tools". 2020. google.com.

https://www.google.com/int//id/inputtools/services/features/transliteration.html.

"Hasil Pencarian - KBBI Daring". 2020. kbbi.kemdikbud.go.id.

https://kbbi.kemdikbud.go.id/entri/Transliterasi.

Mat, Azman, and Ahmad Yaakub. 2020. "Kegunaan Transliterasi Dalam Pengajaran Dan Pembelajaran Bahasa Arab". Ejournal.Ukm.My.

http://ejournal.ukm.my/gema/article/view/107.

2020. Ebook.

https://www.google.com/url?q=http://staffnew.uny.ac.id/upload/132303685/pendidikan/materi transliterasi.pdf\&sa=U\&ved=2ahUKEwjYnljvubrsAhXO6XMBHSjHB2UQFjABegQICXAB\&us g=AOvVaw3NJJNeht BiKWm339053q1.

al-Syā'ir, Ḥ., 2020. Hadīṣ Al-Rasūl (Șallā Allāh 'Alaih Wasallam): "Anā Afșaḥ Al-'Arab Baida Annī Min Quraisy" Sanaduhu Wa Riwāyatuhu Wa Ra'Yu Al-'Ulamā' Fīhi -- Dalālatuhu. [online] Journals.uokufa.edu.iq. Available at: $<$ http://journals.uokufa.edu.iq/index.php/arll/article/view/2307/1972> [Accessed 17 October 2020].

Alekhbariya.net. 2020 [ لماذا سميت اللغة العربية بلغة "الضاد"؟ | الإخبارية. <http://alekhbariya.net/ar/node/38461\#: :text=\%D8\%B3\%D9\%85\%D9\%8A\%D8\%AA\%20\% 
D8\%A7\%D9\%84\%D9\%84\%D8\%BA\%D8\%A9\%20\%D8\%A7\%D9\%84\%D8\%B9\%D8\%B1\%D 8\%A8\%D9\%8A\%D8\%A9\%20\%D8\%A8\%D9\%80\%20\%E2\%80\%9D\%20\%D9\%84\%D8\%BA \%D8\%A9,\%D8\%A8\%D8\%A7\%D9\%84\%D9\%85\%D8\%B9\%D8\%A7\%D9\%86\%D8\%A7\%D8 \%A9\%D8\%8C\%20\%D9\%83\%D9\%85\%D8\%A7\%20\%D8\%A3\%D9\%86\%20\%D8\%A7\%D9\% 84\%D8\%A3\%D8\%B4\%D8\%AE\%D8\%A7\%D8\%B5\%20\%D8\%A7\%D9\%84\%D8\%B0\%D9\%8 A\%D9\%86> [Accessed 17 October 2020].

www.alukah.net. 2020. حديث: أنا أفصح من نطق بالضاد بيد أني من قريش. Wonline] Available at: <https://www.alukah.net/sharia/0/51166/> [Accessed 17 October 2020].

Hasan 'Abd al-Majīd 'Abbās al-Syā'ir, 2020. Hadīṣ Al-Rasūl (Ṣallā Allāh 'Alaih Wasallam): "Anā Afșaḥ Al-'Arab Baida Annī Min Quraisy" Sanaduhu Wa Riwāyatuhu Wa Ra'Yu Al-'Ulamā' Fīhi -- Dalālatuhu. [online], Journals.uokufa.edu.iq. 159. Available at: $<$ http://journals.uokufa.edu.iq/index.php/arll/article/view/2307/1972> [Accessed 17 October 2020].

Pedoman Transliterasi Arab Latin. 2003. Jakarta: Departemen Agama RI, Badan Litbang Agama dan Diklat Keagamaan, Proyek Pengkajian dan Pengembangan Lektur Pendidikan Agama. 